\title{
ÍNDICE DE COBERTURA VEGETAL ATRAVÉS DO NDVI NA MICROBACIA DO RIACHO FLAMENGO, GARANHUNS-PE
}

\author{
Elaynne Mirele Sabino de França ${ }^{(a)}$, Josefa Eliane Santana de Siqueira Pinto ${ }^{(b)}$ \\ (a) Pós-graduação em Geografia, Universidade Federal de Sergipe, emirele.franca@ gmail.com \\ (b) Professora do programa de Pós-graduação em Geografia, Universidade Federal de Sergipe, josefaeliane @ufs.br
}

Eixo: Uso e ocupação das terras e legislação ambiental

\begin{abstract}
Resumo
O objetivo da pesquisa foi identificar e traçar um comparativo multi-temporal do grau de cobertura vegetal na microbacia do Riacho Flamengo em Garanhuns, Pernambuco. Através da aplicação do Índice de Vegetação da Diferença Normalizada (NDVI) pode ser espacializado e quantificado o índice representado pela intensidade, variando de alta, média e baixa, tendo como apoio as ferramentas do geoprocessamento. Para isso tomou os anos de 1991, 2000 e 2010 para traçar um comparativo multitemporal. O desmatamento tem firmado sua concretização no espaço, onde a microbacia possui menos de $30 \%$ da sua área com vegetação. De modo significativo a variável correspondente a média tem predominância em relação as outras, sabendo que depõe sobre vegetação de porte mediano caracterizada por fragmentos dispersos, agricultura e pastagem, estando acima de $50 \%$ da área. A degradação do ambiente pressupõe do desmatamento.
\end{abstract}

Palavras chave: Vegetação; NDVI; Microbacia.

\section{Introdução}

O ambiente, composto pelos elementos naturais e sociais, vem sendo palco da inteferência antrópica. Em vista disso, pressupondo o caráter interdependente dos elementos constituintes do conjunto integrado, qualquer transformação dependendo do nível de tensão imposta acarreta desequilíbro em cadeia (DREW, 1995).

O manto formado pela vegetação disposto na superfície da Terra vem a ser uma camada protetora, servindo para dimunuir o impacto provocado pela chuva quando chega ao solo, aumentando o potencial de infiltração da água e reduzuindo a velocidade e quantia de sedimentos transportados pelo escoamento superficial (BOTELHO, 2015).

Em sua ausência, considerando a interação conjuntiva com o solo e a água, vem a sofrer por processos negativos como: erosão do solo, desencadeando o surgimento de feições de ravinas e voçorocas, e aos recursos hídricos, a partir do transporte e deposição de sedimentos, confirmado pelo assoreamento dos rios e poluição das águas (DREW, 1995; BOTELHO, 2015). 
Para Carvalho (2012) o desmatamento é um dos processos causadores da degradação ambiental. Pois ocorre no intuito de atender questões humanas no contexto social, econômico e ambiental, assinalado respectivamente com a expansão urbana, desenvolvimento de atividades agrícolas e pecuárias, e manutenção da flora e fauna. A intensidade com que se propaga vai repercurtir no sistema.

Diante do disso, faz-se ser relevante a espacialização da densidade de cobertura vegetal como subsídio a degradação ambiental. O índice de vegetação representa componente biofísico vegetal, permitindo indicar índice de área foliar (IAF), a área cobertura vegetal e outros (JENSEN, 2009).

Dos encontrados na literatura, o Índice de Vegetação da Diferença Normalizada (NDVI) tem assumido ser significante ferramenta de apoio para o desenvolvimento de estudos voltados a monitorar a vegetação em diferentes períodos temporais. Vem sendo aplicada no âmbito de pesquisas orientadas a questão climática e florestal (PONZONI; SHIMABUKORO, 2009).

A expressão espacial da vegetação, apresentado pelo índice de cobertura vegetal (ICV), o confirma como parâmetro que permiti identificar e traçar um comparativo das variações espaciais que sucederam com a metamorfose ou supressão da vegetação no espaço e tempo (PINHEIRO, 2011; MELO; SALES; OLIVEIRA, 2011; LOURENÇO, 2013).

Além do mais, a depender do valor quali-quantitativo, através do ICV pode ser constatado e correlacionado ao nível de proteção do solo perante a interação dos componentes físicos da paisagem (PINHEIRO, 2011; BOTELHO, 2015).

Assim, o objetivo aqui foi identificar e traçar um comparativo multi-temporal do grau de cobertura vegetal na microbacia do Riacho Flamengo a partir da aplicação do Índice de Vegetação da Diferença Normalizada. Dessa forma pode ser compreendida a dinâmica da presença da vegetação tensionada pelas derivações antrogênicas.

\section{1 Área de estudo}

A Microbacia do Riacho Flamengo tem sua localização geográfica total em Garanhuns no estado de Pernambuco como pode ser visto na figura 1 . O município ocupa uma área territorial de $458,55 \mathrm{~km}^{2}$, delimitado nas coordenadas geográficas $-8^{\circ} 53^{\prime} 25^{\prime}$ ' de latitude Sul e $-36^{\circ} 29^{\prime} 34^{\prime \prime}$ de longitude Oeste (CPRM, 2005). 


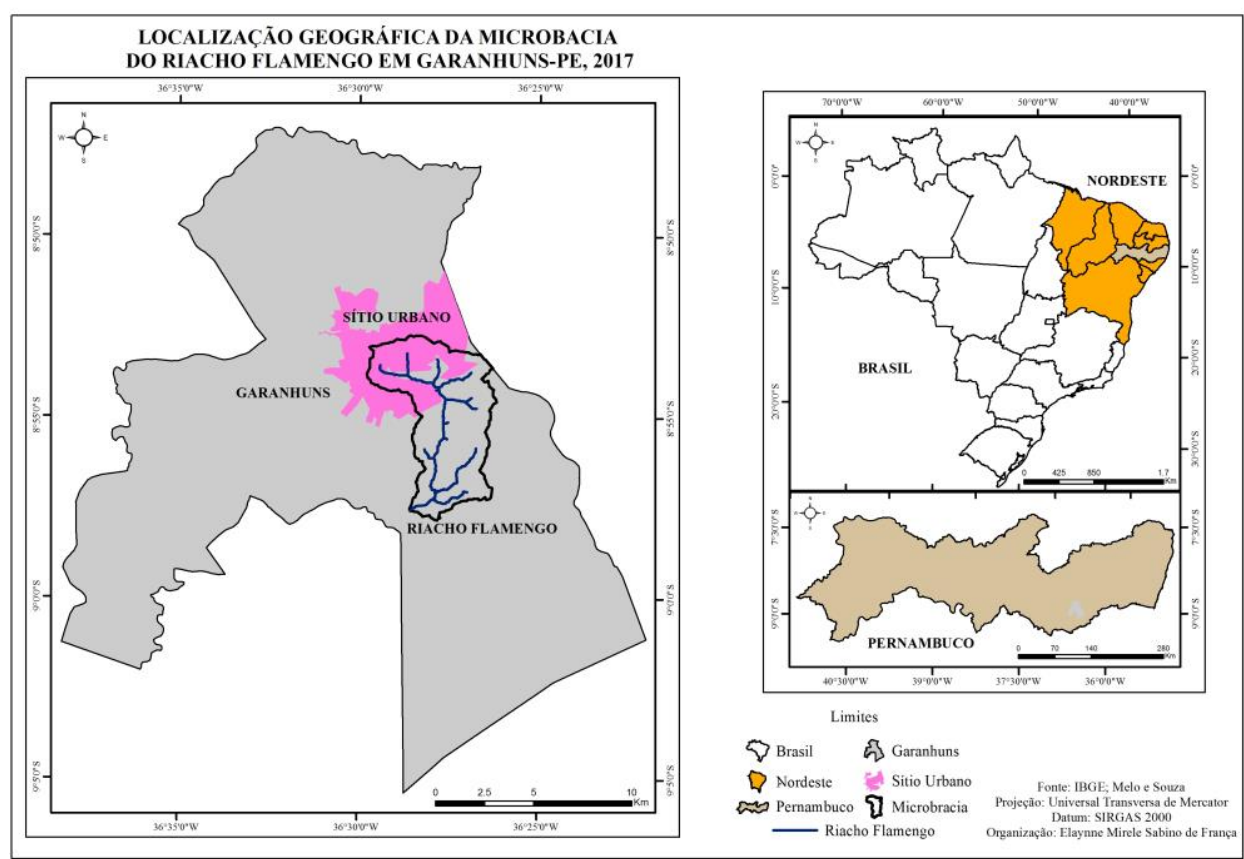

Figura 1: Localização geográfica da microbacia do Riacho Flamengo em Garanhuns, Pernambuco.

As condições climáticas resultam também da influência geomorfológica, por está no planalto da Borborema apresenta elevações que em determinados pontos chega ser superior a 1000 metros. O contato direto entre a região do semiárido e zona da mata pernambucana, o agreste de Pernambuco, engloba Garanhuns na parte da linha de tensão ecológica do Nordeste.

A altitude presente na microbacia varia de 690 a 940 metros, com feições de vales bem delimitados. A vegetação encontrada destaca particularidades de Mata, característica de Floresta Estacional Semidecidua, e Caatinga, com arbóreo-arbustivo.

\section{Procedimento metodológico}

Para atender o objetivo da pesquisa, a princípio foi realizado o levantamento bibliográfico em revistas científicas, anais de eventos, livros e dissertações que dizem respeito à temática como indicativo de orientar e fazer refletir sobre as concepções teóricas e metodológicas pertinentes.

Por seguinte, fez-se o levantamento da base de dados cartográficas no endereço eletrônico Instituto Brasileiro de Geografia Estatística (IBGE) - http://mapas.ibge.gov.br/bases-e-referenciais/basescartograficas/cartas - sobre a delimitação política administrativa.

E de dados espaciais das imagens do satélite LANDSAT 5 descarregado no endereço eletrônico do catálago do Instituto Nacional de Pesquisas Espaciais (INPE) - http://www.dgi.inpe.br/CDSR/index.php 
- pertencente a órbita/ponto 215/66 registrada em Dezembro de 1991 e 2000 e Setembro de 2010, numa resolução espacial de 30 metros.

Os dados obtidos merecem atenção em virtude de apresentarem distorções sistemáticas que carecem passar pelo processamento digital das imagens e em vias de atender o propósito do estudo. Para isso, foram executadas: a correção geométrica, calibração radiométrica e estimativa da reflectância.

\subsection{Correção Geométrica}

A aplicação da correção geométrica se faz para remover a presença de erros, devido a distorções sistemáticas na imagem. Segundo D`Alge (2001) isso vem a ser aspecto indispensável para estudos multitemporal.

Ansiando fazer uma combinação em diferentes tempos, pressupõe incorporar características cartográficas a partir de um sistema de projeção e coordenadas geográficas. Ou seja, fazer o registro e georreferenciamento da imagem por conta de que mesmo sendo de sensor semelhante as imagens apresentam distorções que precisam ser equiparadas.

O registro foi executado através identificação de pontes de controle, efetuado com o auxílio de imagem GeoCover ortorretificada e registrada. Adotando o Sistema de Referência Geocêntrico para as Américas (SIRGAS) 2000, considerado o sistema geodésico de referência oficial do Brasil, com projeção Universal Transversa Mercator (UTM), na zona 24 Sul.

\subsection{Calibração Radiométrica}

Uma imagem composta por bandas espectrais dadas em números digitais, cada banda tem sua especificidade em valor de radiância, como a banda $6(10,4-12,5 \mu \mathrm{m})$ que apresenta contrastes térmicos e as outras destacam uma reposta específica, logo são diferentes. Segundo Ponzoni, Shimabukuro e Kuplich (2012) para mitigar essa limitação, quando for comparar as bandas de outra imagem, com a conversão de números digitais para valores físicos.

A execução dessa conversão segue fórmula indicada por Chander, Markham e Barsi (2007):

$$
L_{\lambda}=\left(\frac{\operatorname{LMAX}_{\lambda}-\mathrm{LMIN}_{\lambda}}{255}\right) Q_{\mathrm{cal}}+\mathrm{LMIN}_{\lambda}
$$


Onde:

$\mathrm{L}_{\lambda}:$ Espectro espectral na abertura do sensor $\left[\mathrm{W} /\left(\mathrm{m}^{2} \cdot \mathrm{Sr} \cdot \mu \mathrm{m}\right)\right]$

$\operatorname{LMAX}_{\lambda}$ : Espectro espectral que é escalado para Qcalmax $\left[\mathrm{W} /\left(\mathrm{m}^{2} \cdot \mathrm{Sr} \cdot \mu \mathrm{m}\right)\right]$;

$\mathrm{LMIN}_{\lambda}$ : Espectro radiante que é dimensionado para Qcalmin $\left[\mathrm{W} /\left(\mathrm{m}^{2} \cdot \mathrm{Sr} \cdot \mu \mathrm{m}\right)\right]$;

$\mathrm{Q}_{\text {cal: }}$ Valor quantificado calibrado de pixel [DN].

\subsection{Estimativa da Reflectância}

Posterior ao cálculo da radiância procede para calcular a reflectância. Compreendida quando o objeto refletiu a radiação eletromagnética recebida. Esse parâmetro assume relevante papel para estudos voltados a vegetação (PONZONI; SHIMABUKURO; KUPLICH, 2012).

A realização do cálculo da reflectância se faz com aplicação da seguinte fórmula (CHANDER; MARKHAM, 2003):

$$
\rho_{P}=\frac{\Pi \bullet L_{\lambda} \bullet d^{2}}{E S U N_{\lambda} \bullet \cos \theta_{s}}
$$

Onde:

९p: Refletância planetária sem unidade;

L $\lambda$ : Radiância espectral na abertura do sensor;

d²: Distância entre a Terra e o Sol em unidades astronômicas;

ESUN $\lambda$ : Radiações solares exoatmosféricas;

@s: Ângulo zênico solar.

Depois de completados os passos acima, o próximo ponto é a aplicação do índice de vegetação da diferença normalizada. O NDVI é obtido a partir da aplicação da seguinte fórmula (PONZONI; SHIMABUKURO; KUPLICH, 2012):

$$
\mathrm{NDVI}=\left(\mathrm{P}_{\mathrm{IVP}}-\mathrm{P}_{\mathrm{V}}\right) /\left(\mathrm{P}_{\mathrm{IVP}}+\mathrm{P}_{\mathrm{V}}\right)
$$

Onde:

NDVI: Índice de Vegetação da Diferença Normalizada;

PIvP: Banda do infravermelho próximo; 
XVII Simpósio Brasileiro de Geografia Fisica Aplicada

I Congresso Nacional de Geografia Física
OS DESAFIOS DA GEOGRAFIA FÍSICA NA FRONTEIRA DO CONHECIMENTO

Instituto de Geociências - Unicamp

Campinas - SP

28 de Junho à 02 de Julho de 2017

$\mathrm{P}_{\mathrm{v}}$ : Banda vermelha.

A relação entre a banda do infravermelho próximo $(0,76-0,90 \mu \mathrm{m})$ e vermelho $(0,63-0,69 \mu \mathrm{m})$, caracterizada por conta de a primeira viabilizar o espalhamento da radiação nas folhas provocando alta reflectância da vegetação e na superfície alta absorção; e a outra porque a influência atmosférica ocorre em proporções menores quando comparadas com a banda azul ou verde permitindo diferenciar a presença ou não da vegetação (PONZONI; SHIMABUKURO; KUPLICH, 2012; NOVO, 2010).

Os valores encontrados são expressos numa variação de tonalidades de cinza, com valores de -1 a +1 . Conforme Ponzoni, Shimabukuro e Kuplich (2012) aquele pixel que tiver valor alto tem expressão de tons mais claros e os de tons escuros dizem respeito sobre os valores mais baixos, sabendo que o valor elevado possui maior quantidade de vegetação e o baixo com área de quantia menor.

O resultado dessa operação matemática passou por processo de reclassificação, onde ocorreu o agrupamento dos valores e correspondência com as classes atribuídas para determinação do ICV. As classes foram indicadas em três formas: alta, média e baixa.

Entendidas de maneira diretamente proporcional: Alta - corresponde a presença de vegetação de modo denso, podendo ser visualizada em florestas; Média - trata do espaço que possui vegetação, no entanto de modo pouco intenso, com representatividade de vegetação esparsa e predomínio de vegetação rasteira (campos); Baixa - vem a ser o local em que não possui a presença de vegetação, designada por áreas urbanas e de solo exposto.

\section{Resultado e Discussão}

Diante do exposto acima, nessa parte são apresentados os resultados que foram constatados nos anos de 1991, 2000 e 2010, respectivamente, sobre a espacialização do índice de cobertura vegetal presente na microbacia. Na figura 1 pode ser visualizada a localização geográfica da presença dos índices. 

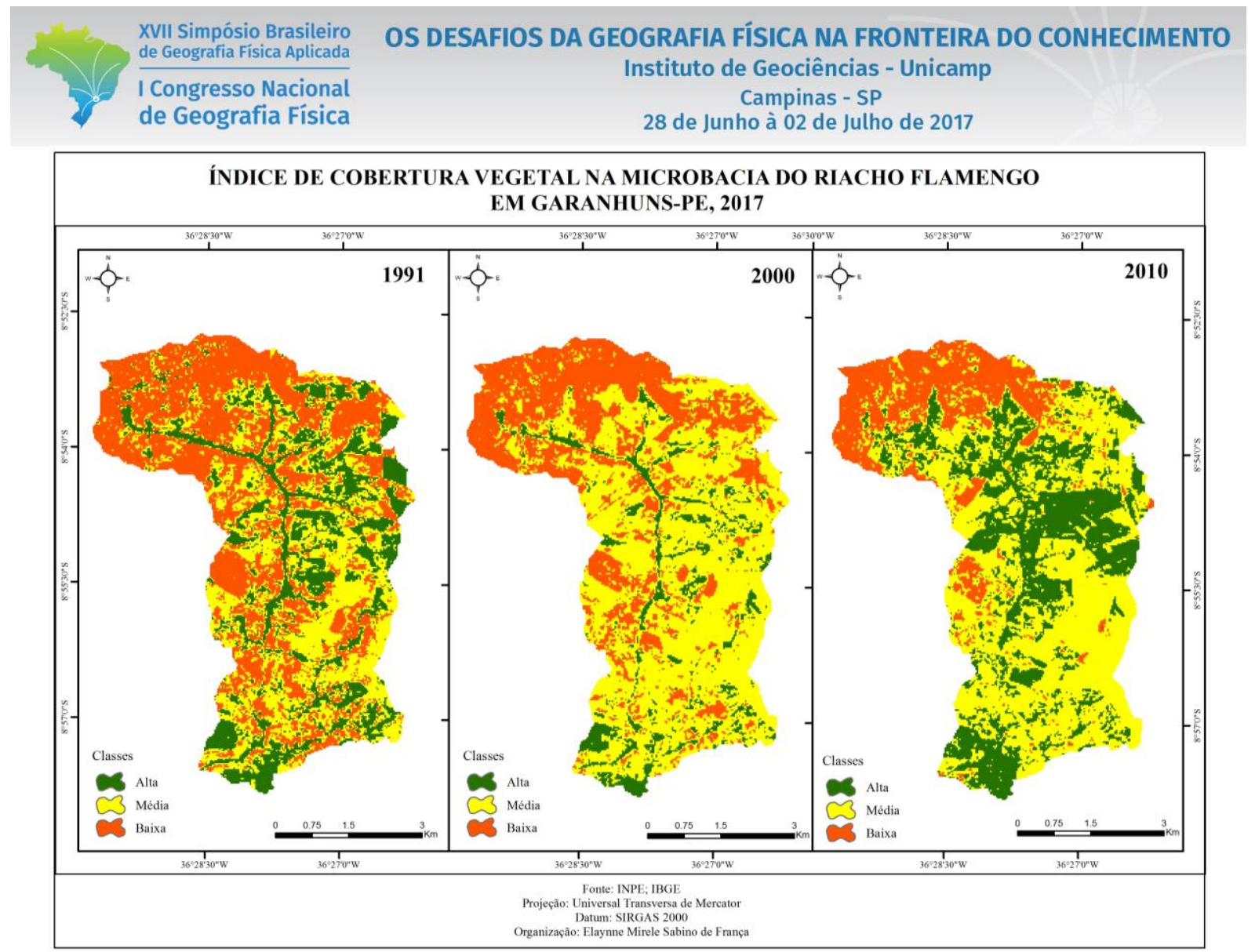

Figura 2: Índice de Cobertura Vegetal da microbacia para os anos 1991, 2000 e 2010.

Em 1991 tem notória expressão ICV a classe correspondente a baixa, com área de 14.910 Km², chegando a atingir um percentual de $41,7 \%$ do total. Seguido pela média, com $12.680 \mathrm{Km}^{2}$, e alta de $8.191 \mathrm{~km}^{2}$. Esses valores indicam a vegetação tem presença mínima para esse ano, com $22,9 \%$, como pode ser visto na tabela I.

Tabela I: ICV (Índice de Cobertura Vegetal) em 1991.

\begin{tabular}{lcc}
\hline \multicolumn{3}{c}{ ICV em 1991 } \\
\hline Classe & Área em km² & Área em \% \\
\hline Alta & $8.191,17$ & 22,9 \\
Média & $12.680,20$ & 35,4 \\
Baixa & $14.910,31$ & 41,7 \\
\hline
\end{tabular}

Observando os valores da tabela II do ano 2000 a transformação da cobertura vegetal apresenta a média como em primeiro plano com $20.994 \mathrm{Km}^{2}$, representando $58,7 \%$ do saldo. Em segundo a baixa, com variada redução do valor que passa a ser $11,404 \mathrm{Km}^{2}$ e de modo expressivo a classe alta fica abaixo dos $10 \%$ do percentual, com de apenas $3.373 \mathrm{Km}^{2}$. 
Tabela II: ICV (Índice de Cobertura Vegetal) em 2000.

$$
\text { ICV em } 2000
$$

\begin{tabular}{lcc}
\hline Classe & Área em $\mathbf{~ k m}^{\mathbf{2}}$ & Área em \% \\
\hline Alta & $3.373,97$ & 9,4 \\
Média & $20.994,70$ & 58,7 \\
Baixa & $11.404,24$ & 31,9 \\
\hline
\end{tabular}

E para o ano 2010, a classe média permanece como maior área de expressão, como deve ser consultada a tabela III, com área de $18.416 \mathrm{Km}^{2}$. Apesar disso a alta demonstra reação quando salta para $10.715 \mathrm{Km}^{2}$ representando percentual de $20 \%$ a mais quando comparado ao ano de 2000 . Por fim, a baixa ficou com $6.648 \mathrm{Km}^{2}$.

Tabela III: ICV (Índice de Cobertura Vegetal) em 2010

\begin{tabular}{lcc}
\hline \multicolumn{3}{c}{ ICV em 2010 } \\
\hline Classe & Área em km $\mathbf{~ k m}^{\mathbf{2}}$ & Área em \% \\
\hline Alta & $10.715,31$ & 29,9 \\
Média & $18.416,2$ & 51,5 \\
Baixa & $6.648,78$ & 18,6 \\
\hline
\end{tabular}

A constante variação ocorrida entre as classes durante os anos analisados demonstra que a média tem mantido nível desenvolvimento crescente, chegando a valores que superam as demais classes indicadas como ficou mais bem visualizado na figura 3 .

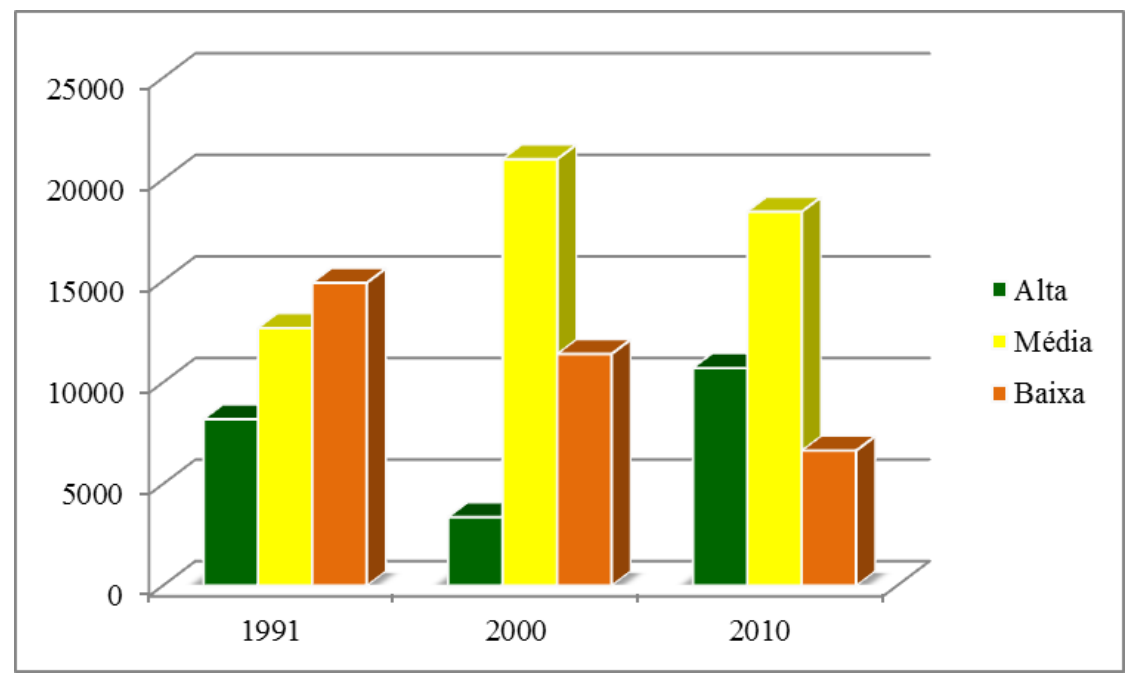

Figura 3: Gráfico da disposição do ICV durante 1991, 2000 e 2010, respectivo a variação das classes: alta, média e baixa. 


\section{OS DESAFIOS DA GEOGRAFIA FÍSICA NA FRONTEIRA DO CONHECIMENTO \\ Instituto de Geociências - Unicamp \\ Campinas - SP \\ 28 de Junho à 02 de Julho de 2017}

Os valores da classe alta estiveram abaixo das demais classes, tal fato confirma o processo de desmatamento na microbacia vem sendo constate e intenso, pois não consegue ultrapassar a faixa de $30 \%$ do percentual das terras que possuem cobertura vegetal.

Isso ainda expõe a fragilidade ambiental da área no que diz respeito aos processos de degradação ambiental e sobre sua capacidade de responder de forma positiva a ações degradativas.

Mesmo que no último ano, em 2010, seja observada a maior taxa, correspondendo a 29,9\%, dando indicativo de regeneração da vegetação, seja reflexo de ações ambientais preocupadas com o avanço do desmatamento e aplicabilidade da legislação ambiental disposta no Novo Código Florestal ou na Politíca Nacional dos Recursos Hídricos.

Passando para a classe média, corresponde à vegetação de porte mediano a baixo, ressalta vestígios de espécies pontuais com expressão não tão significativa, visto que não comporta capacidade suficiente de suprir e despenhar suas funções perante a área.

Demonstra o aprofudamento de uso da terra destinado à prática de atividade agropecuária, principalmente a expansão do setor pecuário, destinando maior parte da terra para a criação de gado. Assim promove a possibilidade para o desencadeamento ou intensificação da ocorrência de compactação do solo, processos erosivos e diminuição do aproveitamento das águas com a redução da capacidade de infiltração é iminente.

O desmatamento para ceder lugar a essas atividades, realizadas de forma intensa, vem a provocar desgate e empobrecimento do solo, assoreamento dos rios e poluição dos recursos hídricos. Para Carvalho (2012) a retira da vegetação constituiu um dos principais problemas enfrentados nas bacias hidrográficas.

Nesse quadro ainda pode ser tomadas iniciativas paleativas com observância de no minímo conservar as áreas de preservação permante de nascentes e cursos d’água, proteção dos locais que ainda tem a presença de floresta densa e reflorestamento de locais que já apresentam risco a segurança social e ambiental.

Por fim, a classe baixa demonstra decréscimo chegando representar 18,6\% da área. Desse dado, relacionado diretamente a área urbana e solo exposto, incorre saber que o município onde fica a microbacia apresenta taxa de crecimento de população para os anos analisados. Conforme o IBGE, no censo demográfico em 1991, Garanhuns tinha uma população de 103,341 mil habitantes; em 2000 houve aumento somando mais 10.000 habitantes, com total de 117,749 mil habitantes; e em 2010 de 129,408 mil habitantes. 


\section{Considerações Finais}

A utilização dos meios tecnológicos possibilitados pelos dados espaciais tem se tornado ferramenta de grande valor para o desenvolvimento de estudos em busca de fazer apreciação sobre a cobertura vegetal e realizar um comparativo entre anos de forma eficiente e rápida.

O índice de vegetação traduz marcantemente a dinâmica de dado lugar, assim como depõe dando indicativo de questões sobre como anda o nível de conservação vegetal. Esse fator implica nos demais componentes da paisagem, quando refletida a luz da conexão interdependente que possui.

A microbacia chegou a patamar de espaço geográfico amplamente modificado, estabelecido pela relação sociedade e natureza, visto que o desmatamento tem o intuito de suprir necessidades sociais e econômicas, seja com expansão urbana ou atividades agropecuárias.

Os desequilíbrios provenientes com a metamorfose do espaço requer ações de monitoramento da vegetação, manejo do solo compatível com a legislação ambiental vigente, pois já seria grande passo para assegurar a proteção do solo e das águas, bem como a conservação da natureza e manutenção da biodiversidade.

\section{Bibliografia}

BOTELHO, R. G. M. Planejamento ambiental em microbacia hidrográfica. In: GUERRA, A. J. T. SILVA, A. S.

BOTELHO, R. G. Erosão e conservação dos solos: conceitos, temas e aplicações (org.). 10 a ed. Rio de Janeiro: Bertrand Brasil, 2015. p. 269-300.

CARVALHO, R. G. Sistemas ambientais e desmatamento na região da bacia hidrográfica do rio ApodiMossoró/RN. Revista da ANPEGE, v.8, n.9, jan/jul, 2012. p. 107-118.

D’ALGE, J. C. L. Cartografia para geoprocessamento. In: CÂMARA, G.; DAVIS, C.; MONTEIRO, A. M. V. Introdução à Ciência da Geoinformação. São José dos Campos, INPE, 2001 (on-line, 2a. edição, revista e ampliada).

DREW, D. Processos interativos homem-meio ambiente. São Paulo: DIFEL, 1995.

JESEN, J. R. Sensoriamento remoto da vegetação. In: JESEN, J. R. Sensoriamento remoto do ambiente: uma perspectiva em recursos terrestres. São José dos Campos, SP: Parêntese, 2009.

LOURENÇO, Ronaldo Mendes. Diagnóstico físico-conservacionista como aporte para a análise da degradaçãono médio curso da Bacia Hidrográfica do Rio Aracatiaçu (CE). 2013. 170 f. Dissertação (Mestrado) no Programa de Pós-Graduação em Geografia, Universidade Federal do Ceará, Fortaleza.

MELO, E. T; SALES, M. C. L; OLIVEIRA, J. G. B. Aplicação do índice de vegetação por diferença normalizada (NDVI) para análise da degradação ambiental na microbacia hidrográfica do riachos dos cavalos, Crateús-CE. RA`E GA Departamento de Geografia - UFPR, Curitiba, v.23, 2011 p. 520-533.

NOVO, E. M. L. M. Sistemas orbitais. NOVO, E. M. L. M. Sensoriamento remoto: princípios e aplicações. $4^{\mathrm{a}}$ ed. São Paulo: Blucher, 2010. p. 159-238. 


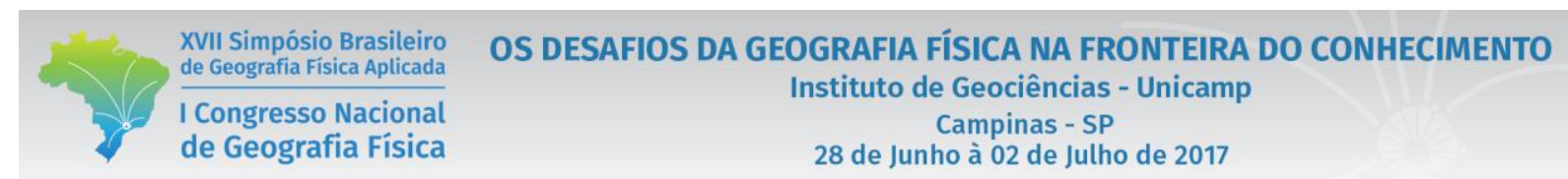

PONZONI, F. J. SHIMABUKURO, Y. E. KUPLICH, T. M. Sensoriamento Remoto da Vegetação. $2^{\mathrm{a}}$ ed. Revisada e ampliada. São Paulo: Oficina de Textos, 2012.

PINHEIRO, R. A. B. Análise do processo de degradação/desertificação na bacia do Riacho Feiticeiro, com base no DFC, município de Jaguaribe-Ceará. 2011. 126 f. Dissertação (Mestrado) no Programa de Pós-Graduação em Desenvolvimento e Meio Ambiente - PRODEMA, Universidade Federal do Ceará, Fortaleza. 